\title{
Visitantes florais do maracujá-amarelo (Passiflora edulis f. flavicarpa Deg. Passifloraceae) em áreas de cultivo com diferentes proximidades a fragmentos florestais na região Norte Fluminense, $R \mathbf{J}$
}

\author{
Cristine Rodrigues Benevides ${ }^{1}$, Maria Cristina Gaglianone ${ }^{1} \&$ Magali Hoffmann $^{2}$
}

\begin{abstract}
${ }^{1}$ Laboratório de Ciências Ambientais (LCA), CBB Universidade Estadual do Norte Fluminense Darcy Ribeiro (UENF), Av. Alberto Lamego, 2000, Campos dos Goytacazes, 28013-602 Rio de Janeiro-RJ, Brasil. crisbenevides@yahoo.com.br; mcrisgag@uenf.br ${ }^{2}$ Laboratório de Entomologia e Fitopatologia (LEF), CCTA Universidade Estadual do Norte Fluminense Darcy Ribeiro (UENF).
\end{abstract}

\begin{abstract}
Yellow passion fruit (Passiflora edulis f. flavicarpa Deg. Passifloraceae) floral visitors in cultivated areas within different distances from forest remnants in north Rio de Janeiro state. This work aimed to identify the main pollinators and study the floral biology of the yellow passion fruit cultivated in areas within different distances from forest remnants in north Rio de Janeiro state. The yellow passion fruit flowering lasted nine months, from September to March. Anthesis started at 12:00 $\mathrm{h}$ and the opening process lasted until 16:30 h. The styles bent down during the anthesis and $72.4 \%$ of the flowers had its styles curved. Nectar was produced continuously, reaching $18 \mu 1 /$ flower/hour, and the total solute concentration varied between 38 and 42\%. Xylocopa frontalis and Xylocopa ordinaria were the most effective yellow passion fruit pollinators because of their visit frequency, intrafloral behavior and body size. These bee species, besides Apis mellifera, were found in all the cultivated areas studied. The highest richness of pollinators was observed in cultivated areas closest to forest remnants. This fact is related to the presence of native bee groups, like Centridini and Euglossina bees (Apidae), which depend on forest areas for nesting and foraging. The forest remnant proximity is also important to provide the nesting and food resources needed by the Xylocopa population during the year.
\end{abstract}

KEYWORDS. Apidae; carpenter bees; forest fragments; Passifloraceae.

\begin{abstract}
RESUMO. Visitantes florais do maracujá-amarelo (Passiflora edulis f. flavicarpa Deg. Passifloraceae) em áreas de cultivo com diferentes proximidades a fragmentos florestais na região Norte Fluminense, RJ. Este trabalho teve como objetivos estudar a biologia floral e identificar os principais polinizadores do maracujá-amarelo em áreas de cultivo com diferentes proximidades a fragmentos florestais no norte do estado do Rio de Janeiro. A floração do maracujá-amarelo teve duração de nove meses, no período de setembro a maio. As flores iniciavam a antese às 12:00 h e abriam-se ao longo do dia até às 16:30 h. O processo de curvatura dos estiletes ocorreu ao longo da antese e 72,4\% das flores curvaram seus estiletes. A produção de néctar deu-se continuamente, atingindo $18 \mu 1 /$ flor/hora e a concentração de solutos totais variou entre 38 e 42\%. Xylocopa frontalis e Xylocopa ordinaria foram os principais polinizadores do maracujá-amarelo pela freqüência de visitas, comportamento intrafloral e porte corporal. Estas espécies de abelhas, além de Apis mellifera, estiveram presentes em todas as áreas de cultivo. A maior riqueza de visitantes polinizadores do maracujá-amarelo foi observada em áreas de cultivo próximas a fragmentos florestais, fato relacionado à presença de certos grupos de abelhas nativas, como Centridini e Euglossina (Apidae) que dependem de áreas florestais para nidificação e alimentação. A proximidade a fragmentos florestais também é importante para o fornecimento de recursos alimentares e de nidificação ao longo do ano para a manutenção de populações de Xylocopa.
\end{abstract}

PALAVRAS-CHAVE. Apidae; fragmentos florestais; mamangavas; Passifloraceae.

A redução da diversidade e abundância dos polinizadores tem recebido maior atenção nos últimos anos devido a sua relevância em ambientes naturais e cultivados; além disso, o entendimento da ecologia das interações destes animais com espécies vegetais é de importância fundamental para programas de desenvolvimento sustentável (Klein et al. 2003; Chacoff \& Aizen 2006). A informação sobre polinização, inclusive de espécies cultivadas, ainda é fragmentada e muitas vezes abrange regiões geográficas limitadas (Roubik 1995; Kevan 1999). Além disso, populações de polinizadores podem estar sujeitas a diferentes pressões antrópicas e a variáveis efeitos da fragmentação florestal.

Os efeitos da fragmentação do habitat devido à expansão da agricultura e pecuária estão entre os principais fatores para o declínio da biodiversidade, incluindo de polinizadores (Debinsky \& Holt 2000; Cresswell \& Osborne 2004). A fragmentação florestal pode isolar populações de polinizadores em áreas florestadas, impedindo o fluxo entre fragmentos e a conseqüente ausência destas espécies nas matrizes no entorno. Além disso, a dependência a recursos das florestas, muitas vezes ausentes em áreas de cultivo, pode resultar no déficit de polinizadores nestas áreas, comprometendo a produção agrícola (Chacoff \& Aizen 2006). Mesmo para polinizadores mais generalistas em relação aos recursos alimentares, a proximidade a fragmentos florestais pode ser necessária para obter recursos como locais específicos de nidificação ou recursos não alimentares (Chacoff \& Aizen 2006).

O maracujá-amarelo, Passiflora edulis f. flavicarpa Deg., é uma espécie cultivada, auto-incompatível, e depende de polinizadores (Teixeira 1994). Estes são abelhas de grande porte do gênero Xylocopa (Apidae) conhecidas popularmente como 
mamangavas-de-toco (Ruggiero 1973; Corbet \& Willmer 1980; Hoffmann et al. 2000). A carência destes polinizadores nativos foi apontada como um dos fatores responsáveis pela baixa produtividade de frutos em diversas regiões (Teixeira 1994; Camillo 2003), obrigando à prática de polinização manual, inclusive na região norte fluminense, RJ. Esta região possui economia essencialmente pecuarista e agrícola e teve a maior parte da cobertura vegetal retirada resultando em áreas de cultivo e pastagem, formando assim, um mosaico de matrizes que cercam pequenos fragmentos florestais (Ferreira et al. 2003). A vegetação original era constituída de florestas semidecíduas, de baixada e de tabuleiro, além de restingas (Rizzini 1979), e atualmente estas áreas estão dispersas em pequenos fragmentos florestais, a maioria com menos de 10 ha.

Este estudo foi desenvolvido com o intuito de identificar as espécies de polinizadores do maracujá-amarelo na região norte fluminense, verificar se a freqüência de polinizadores está relacionada à frutificação natural e avaliar a relação da distância entre as áreas de cultivo e os fragmentos florestais com a riqueza dos polinizadores.

\section{MATERIALE MÉTODOS}

$\mathrm{O}$ estudo foi realizado em áreas de cultivo comercial de maracujá-amarelo no período de outubro de 2004 a setembro de 2005. Foram selecionadas seis áreas de cultivo de Passiflora edulis f. flavicarpa localizadas a diferentes proximidades de fragmentos florestais nos municípios de São Francisco do Itabapoana e Campos dos Goytacazes (RJ) (Fig. 1). As áreas estudadas fazem parte de projetos de incentivo à fruticultura, apresentando padrões semelhantes relativos ao preparo da terra, seleção das sementes, adubação, utilização de inseticidas e plantios em espaldeiras verticais.

As áreas de cultivo selecionadas variaram de 0,4 a 5 ha, sendo que a área delimitada para o estudo variou de $910 \mathrm{~m}^{2}$ a $14430 \mathrm{~m}^{2}$. A distância das áreas de cultivo aos fragmentos florestais mais próximos variou de $10 \mathrm{~m}$ a 3,6 Km. Os fragmentos florestais são remanescentes de mata de tabuleiro, com área variando de 2 a 1053 ha (Tabela II). A composição florística e fitossociológica destas florestas foi descrita em Silva \& Nascimento (2001).

Para verificar o período de abertura floral, deflexão dos estiletes e a disponibilidade de recursos, botões em pré-antese $(\mathrm{n}=210)$ foram marcados e acompanhados a cada hora, das $11: 30$ as $16: 30 \mathrm{~h}$ por quatro dias. As flores foram classificadas como fechada ou aberta, as anteras com ou sem pólen e os estiletes como sem curvatura (SC), parcialmente curvos (PC) ou totalmente curvos (TC), conforme denominação proposta por Ruggiero (1973).

Para a verificação do volume de néctar produzido ao longo do dia, cinco flores previamente ensacadas tiveram o conteúdo total de néctar retirado a cada hora, das $11: 30$ as $17: 30 \mathrm{~h}$, com seringas de $0,3 \mathrm{ml}$ graduadas e microcapilares de $5 \mu \mathrm{l}$ graduados. A concentração de solutos totais no néctar foi medida com o auxílio de um refratômetro manual em intervalos de uma hora. Para verificar o volume total do néctar ao fim do dia, outras cinco flores previamente ensacadas foram aferidas no final da tarde.
Visando avaliar a frequiência dos visitantes florais em cada área de estudo, as flores foram inspecionadas por dois observadores caminhando entre as fileiras de cultivo, em velocidade constante, iniciando em pontos distintos na borda e interior da área no período de maior atividade de forrageio dos visitantes, das 12:00 as 14:00 h por 12 dias (24 horas de observação) e das 12:00 as 16:30 h por 7 dias (28 horas de observação) totalizando 52 horas. Os visitantes observados e o recurso coletado foram anotados, além do número de flores presentes na área percorrida. Para comparar a frequiência de visitas nas diferentes áreas de estudo, foi calculado o número de visitas por flor realizadas por cada espécie, tomando-se a frequiência absoluta em intervalos de 30 minutos e dividindoa pelo número de flores observado no mesmo período.

O comportamento dos visitantes foi estudado por observações diretas e através de registros por fotografias e filmagens durante as visitas às flores. Para cada espécie de visitante foram registrados o local de pouso na flor, recurso coletado e comportamento intrafloral. Durante este período alguns visitantes foram coletados para identificação taxonômica, medidas de comprimento do corpo e altura do tórax com auxilio de um paquímetro de aço. Para medida do comprimento do corpo, considerou-se a distância entre a extremidade anterior da cabeça e a posterior do abdômen e para a altura do tórax, a maior distância entre suas extremidades. Visitantes florais foram classificados como potenciais polinizadores, quando apresentavam comportamento e tamanho do corpo compatíveis com a morfologia e a biologia floral.

O material testemunho dos visitantes florais foi depositado na Coleção de Zoologia do Laboratório de Ciências Ambientais da Universidade Estadual do Norte Fluminense Darcy Ribeiro (UENF).

A diversidade de espécies foi analisada pelo cálculo do índice de diversidade de Shannon-Wiener (Magurran 1988) comparado entre as áreas de cultivo. As relações entre estes índices e a distância entre os cultivos e os fragmentos florestais, com a riqueza de polinizadores e com a riqueza de visitantes florais foram analisadas através de análise de correlação de Pearson (Zar 1999).

Para verificar a polinização natural, em cada dia de observação após a tomada de dados de freqüência de visitas, 100 flores foram marcadas casualmente e observadas quanto à formação de frutos. Foram realizadas análises de correlação de Pearson (Zar 1999), para verificar a relação entre a porcentagem de polinização natural e a freqüência dos polinizadores e pilhadores mais freqüentes, Xylocopa spp. e Apis mellifera respectivamente.

\section{RESULTADOS}

A floração do maracujá-amarelo na região norte fluminense ocorreu de setembro a junho abrangendo o período anual de maior temperatura média (Fig. 2), entretanto, existiram variações no período de florescimento nas seis áreas amostradas.

As flores não apresentaram sincronia em relação à abertura floral, iniciando o período de antese em torno das $12 \mathrm{~h}$ até as 16:30 $\mathrm{h}$, quando todas as flores estavam abertas. A maior 


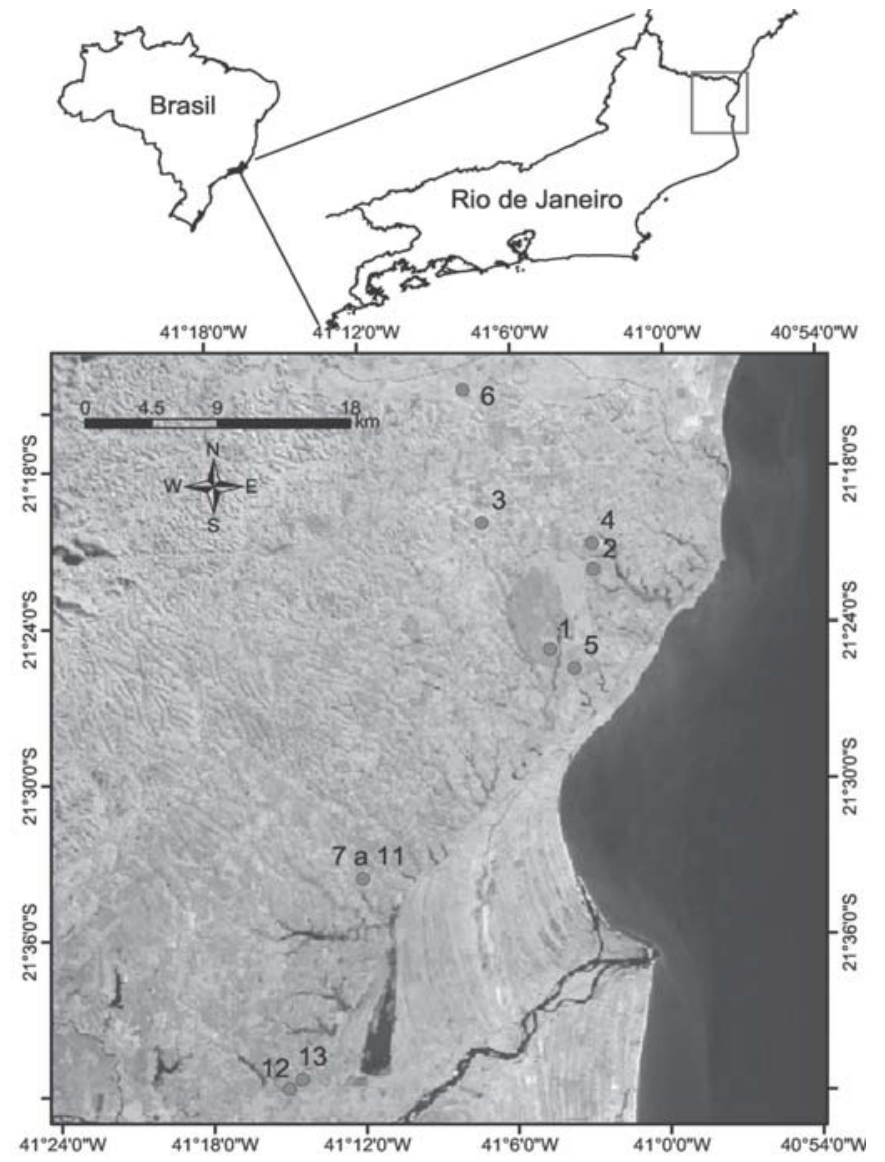

Fig. 1. Localização das áreas de fragmentos nativos de mata de tabuleiro e áreas de cultivo comercial de maracujá-amarelo estudadas nos municípios de São Francisco do Itabapoana e Campos dos Goytacazes, RJ. (1. Mata do Carvão; 2. área do Sr. Raul em São Francisco do Itabapoana; 3. área de cultivo do Sítio Boa Sorte; 4. área de cultivo do Sr. Manoel; 5. área de cultivo da Fazenda São Pedro; 7. Mata do Funil; 8. área de cultivo do Sr. Eli; 9. área de cultivo Sr. Claudiomar; 12 e 13. áreas de cultivo do assentamento Zumbi. Áreas 6, 10 e 11 não foram utilizadas neste estudo.

freqüência de abertura ocorreu entre 12:00 e 14:00 h, quando $77 \%$ das flores já estavam abertas. Ao longo da antese, a maior parte das flores observadas curvou seus estiletes, sendo que por volta de $16: 30 \mathrm{~h}, 72,4 \%$ das flores apresentaram-se com os estiletes totalmente curvos, $19 \%$ com os estiletes parcialmente curvos e 8,6\% de estiletes sem curvatura (Fig. 3).

$\mathrm{O}$ volume e concentração de solutos do néctar acumulado durante toda a antese chegaram a $75 \mu \mathrm{l} \mathrm{e} 42 \%$, respectivamente (Fig. 4). A produção de néctar ocorreu continuamente e o maior volume médio foi registrado entre 12:30 e 14:30 h, com pico de produção neste horário (média de $18 \mu$ l por flor por hora), e declínio posterior, chegando a menos de $5 \mu \mathrm{l}$ por flor por hora, depois de 15:30 h. A concentração média de solutos totais variou ao longo do dia entre 38 e $42 \%$, diminuindo após as 14:30 h simultaneamente com o volume de néctar. A freqüência de visitas dos polinizadores e pilhadores foi maior das 11:30 as 14:30 h, após este período a atividade dos visitantes florais foi muito baixa (Fig. 5).

Xylocopa frontalis (Olivier, 1789), Xylocopa ordinaria
Smith, 1874 e Apis mellifera Linnaeus, 1758 foram encontradas em todas as áreas de cultivo estudadas, sendo os visitantes florais mais freqüentes e registrados ao longo de todo período de observação (Tabela I) (Fig. 5). Outras espécies de abelhas de grande porte como Epicharis flava (Friese, 1900), Centris longimana Fabricius, 1804, Centris flavifrons (Fabricius, 1775), Eulaema nigrita Lepeletier, 1841 e Eulaema cingulata (Fabricius, 1804) também visitaram as flores do maracujáamarelo, porém em menor frequiência (Tabela I). Além de abelhas, ocorreram ocasionalmente outros visitantes florais como lepidópteros, dípteros e beija-flores (Tabela I).

No período de outubro a janeiro, a freqüência de visitas de A. mellifera foi superior à freqüência de Xylocopa spp. em todas as áreas estudadas (Fig. 6 A). Além disso, foi observado que as anteras rapidamente após a antese ficavam sem pólen. Diferentemente, no período de fevereiro a maio, a atividade de A. mellifera foi inferior a de Xylocopa spp., apresentando padrão contrário ao observado no período anterior (Fig. 6 B), e foi constatada a permanência de pólen nas anteras durante todo dia de observação.

A porcentagem de polinização natural foi positivamente correlacionada com a freqüência de Xylocopa $\mathrm{spp}$. $(\mathrm{r}=0,68 ; \mathrm{n}$ $=12 ; \mathrm{p}=0,03)$, mas não com a de A. mellifer $a(\mathrm{r}=-0,26 ; \mathrm{n}=12$; $\mathrm{p}=0,1)$ (Fig. 6).

Abelhas de grande porte (tamanho do corpo superior a 1,8 $\mathrm{cm}$ e altura superior a $0,7 \mathrm{~cm}$ ) pertencentes aos gêneros Xylocopa, Eulaema, Centris e Epicharis apresentaram comportamento semelhante nas flores do maracujá-amarelo. Pousavam diretamente sobre as pétalas ou sobre a corona, caminhavam em direção ao centro da flor e introduziam as peças bucais na câmara nectarífera em busca do néctar (Fig. 7A). Podiam repetir este comportamento em outros pontos na câmara nectarífera da mesma flor, rodeando a base do androginóforo, ou levantavam vôo dirigindo-se a outra flor. O contato com anteras e estigmas ocorria sempre na região dorsal do corpo do visitante, no mesoscuto e escutelo. Estas abelhas foram consideradas polinizadores eficientes nas áreas estudadas.

A. mellifera não apresenta tamanho corporal adequado à polinização e buscavam preferencialmente o pólen durante

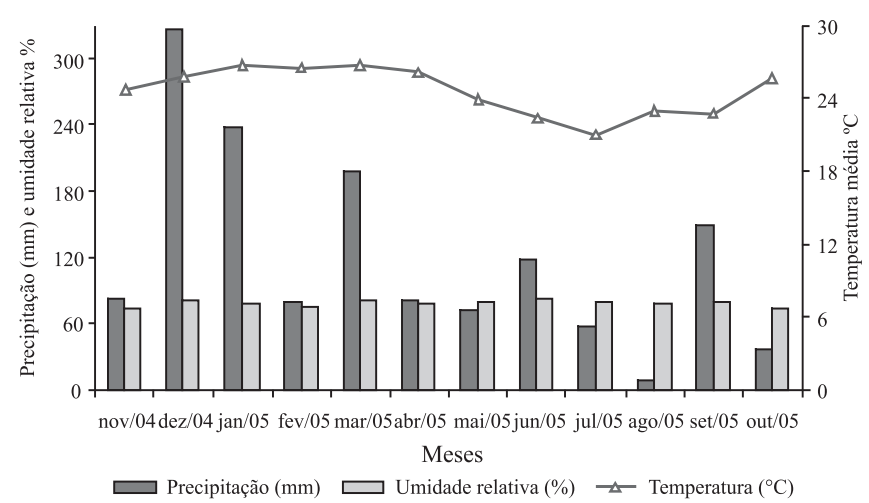

Fig. 2. Dados Climatológicos obtidos na Estação Meteorológica da Prefeitura de Campos dos Goytacazes, RJ, no período de novembro/ 2004 a outubro/2005. 


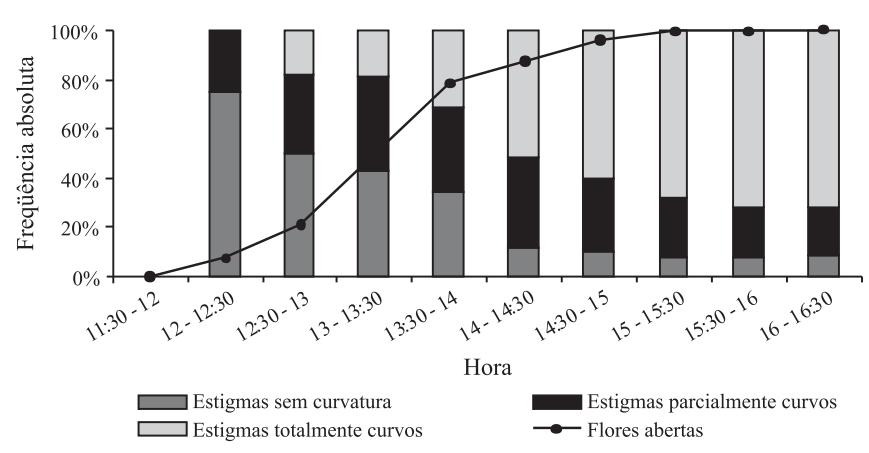

Fig. 3. Freqüência acumulada de flores abertas do maracujá-amarelo Passiflora edulis f. flavicarpa, em períodos de 30 minutos, e porcentagem de flores nos diferentes estágios de curvatura dos estigmas ao longo do dia em duas áreas de cultivo (área 9, n=59 e área 4, n=46 flores).

suas visitas às flores, atuando como pilhadores (Fig. 7B). Neste caso, pousavam diretamente sobre as anteras abertas e com as pernas anteriores e médias retiravam o pólen, acumulandoo nas corbículas. O contato com anteras e estigmas era raro, pois as visitas muitas vezes se restringiam à coleta em uma única antera na mesma flor e geralmente forrageavam em grupo. Estas abelhas também visitavam as flores ainda em pré-antese, quando forçavam a abertura das pétalas e alcançando as anteras antes da abertura floral.

A maior riqueza de polinizadores ocorreu na área 4 , já a diversidade de polinizadores do maracujá-amarelo foi maior $\left(H^{\prime}=0,79\right)$ nas áreas 4 e 5, a 10m e 1,4km da Mata do Carvão, respectivamente. Contudo, quando se correlacionou a distância entre áreas de cultivo e os fragmentos florestais com os índices de diversidade de espécies $(\mathrm{r}=-0,69 ; \mathrm{n}=4 ; \mathrm{p}=$ $0,06 ;)$, com a riqueza de polinizadores $(r=-0,62 ; n=4 ; p=0,11)$ e com a riqueza de visitantes florais $(\mathrm{r}=-0,64 ; \mathrm{n}=4 ; \mathrm{p}=0,08)$, não houve diferença significativa.

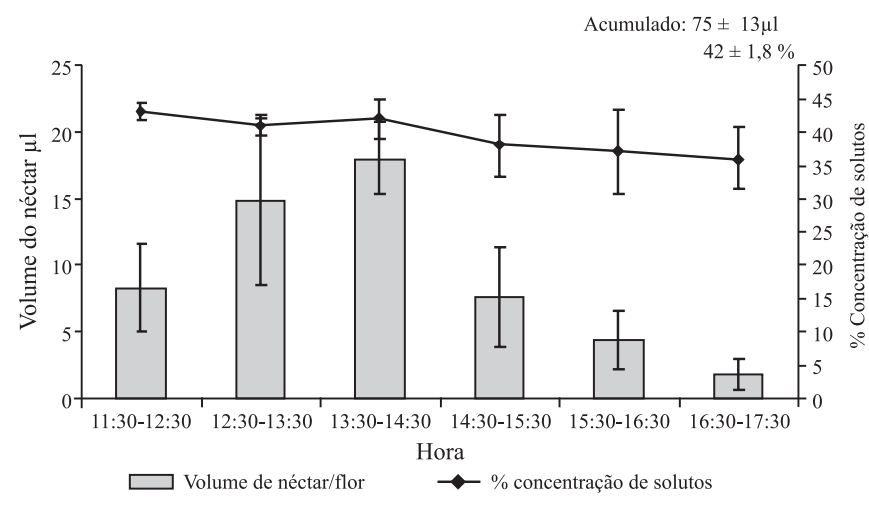

Fig. 4. Volume de néctar e concentração de solutos de Passiflora edulis f. flavicarpa expressos em valores médios \pm desvio padrão tomados em intervalos de hora para 5 flores ao longo do dia em áreas de cultivo nos Municípios de São Francisco do Itabapoana e Campos dos Goytacazes, RJ. Os valores à direita do gráfico representam o total de néctar produzido no dia e a concentração de solutos totais deste volume.

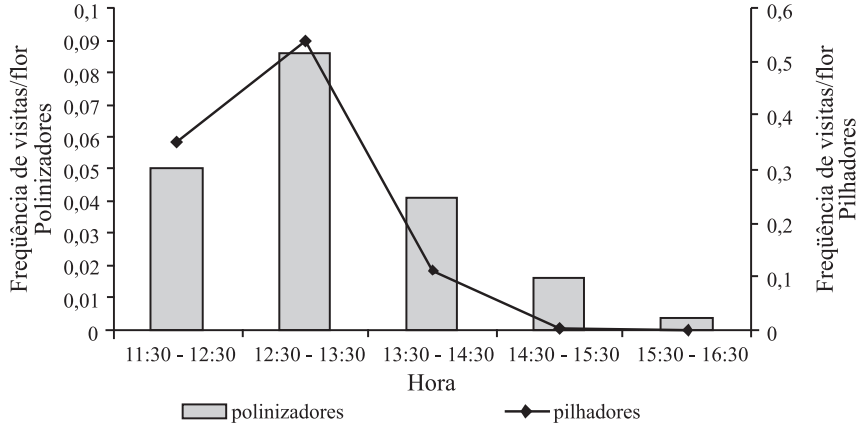

Fig. 5. Freqüência de visitas/flor de Xylocopa spp. e Apis mellifera em flores do maracujá-amarelo (Passiflora edulis f. flavicarpa) das 11:30 às 16:30h em seis áreas de cultivo (19 dias de observação, 52 horas).

\section{DISCUSSÃO}

O florescimento de Passiflora edulis f. flavicarpa na região norte fluminense ocorreu durante nove meses ao longo do ano, semelhante para áreas de cultivo no estado de São Paulo (Vallini et al. 1976; Camillo 2003). O maracujazeiro é uma planta exigente quanto à luminosidade, necessitando de cerca de 12 horas diárias de luz para ocorrer o florescimento (Camillo 2003), justificando sua maior floração nos períodos do ano com maior comprimento do dia e temperatura média (Sousa 1994; Teixera 1994).

A abertura das flores do maracujá-amarelo não é sincrônica e a proporção dos três tipos de flores (com estiletes totalmente ou parcialmente curvos e sem curvatura dos estiletes) varia ao longo do período de abertura floral, sendo que o número de flores com estiletes totalmente curvos aumenta gradativamente
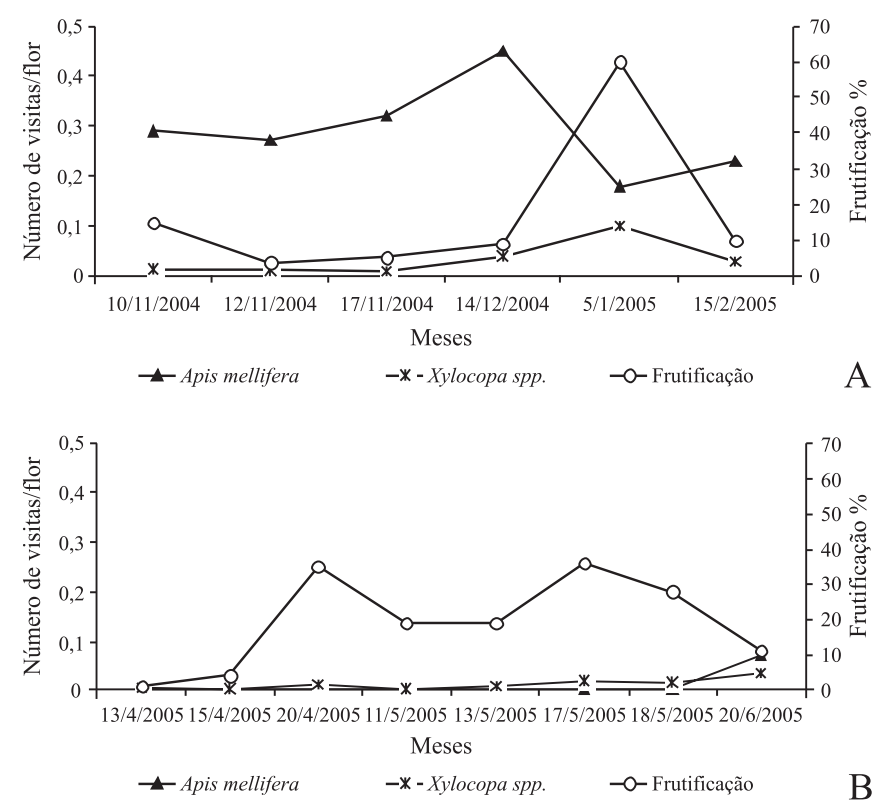

Fig. 6. Frequiência de visitas/flor de Apis mellifera e Xylocopa spp. em flores do maracujá-amarelo (Passiflora edulis f. flavicarpa) e taxa de frutificação em dois períodos diferentes, A: novembro a fevereiro e B: abril a junho, em áreas de cultivo em São Francisco do Itabapoana, RJ. 
Tabela I. Freqüência relativa, áreas de ocorrência e medidas corpóreas dos visitantes florais do maracujá-amarelo Passiflora edulis f. flavicarpa presentes em todas as áreas de estudo nos municípios de São Francisco do Itabapoana e Campos dos Goytacazes, RJ. Localização das áreas na Figura 1 Comp: comprimento do corpo; Alt: altura do tórax.

\begin{tabular}{|c|c|c|c|c|c|}
\hline & Visitantes florais & $\begin{array}{l}\text { Frequiência relativa } \\
\text { média }(\%)\end{array}$ & $\begin{array}{l}\text { Áreas de } \\
\text { ocorrência }\end{array}$ & $\begin{array}{l}\text { Comp } \\
(\mathrm{cm})\end{array}$ & $\begin{array}{l}\text { Alt } \\
(\mathrm{cm})\end{array}$ \\
\hline \multirow{2}{*}{\multicolumn{6}{|c|}{$\begin{array}{l}\text { INSECTA } \\
\text { HYMENOPTERA }\end{array}$}} \\
\hline & & & & & \\
\hline \\
\hline Apini-Apina & Apis mellifera Linnaeus, 1758 & 85 & $2,4,5,8,9$ e 13 & 1,3 & 0,32 \\
\hline \multirow[t]{4}{*}{ Apini-Euglossina } & & $<0,5$ & & & \\
\hline & Euglossa cordata (Linnaeus, 1758) & & 4 & 1,1 & 0,4 \\
\hline & Eulaema nigrita Lepeletier, 1841 & & 5 & 1,9 & 0,79 \\
\hline & Eulaema cingulata (Fabricius, 1804) & & 13 & 2,1 & 0,76 \\
\hline \multirow[t]{4}{*}{ Centridini } & & 0,5 & & & \\
\hline & Epicharis flava (Friese, 1900) & & 4 & 2,2 & 0,79 \\
\hline & Centris flavifrons (Fabricius, 1775) & & 4,9 & 2,1 & 0,80 \\
\hline & Centris longimana Fabricius, 1804 & & 4 & 2,0 & 0,79 \\
\hline \multirow[t]{2}{*}{ Xylocopini } & Xylocopa frontalis (Olivier, 1789) & 8 & $2,4,5,8,9$ e 13 & 2,9 & 1,1 \\
\hline & Xylocopa ordinaria Smith, 1874 & 5 & $2,4,5,8,9$ e 13 & 2,1 & 0,76 \\
\hline HALICTIDAE & & $<0,1$ & & & \\
\hline Augochlorini & Augochloropsis sp. 1 & & 5 & 0,8 & 0,26 \\
\hline \multirow[t]{3}{*}{ VESPIDAE } & & $<0,1$ & & & \\
\hline & & & $2,4,5,8,9$ e 13 & & \\
\hline & Vespidae sp. 1 & & & 2,4 & 0,7 \\
\hline DIPTERA & Syrphidae sp. 1 & 0,1 & 8,9 & 0,9 & 0,2 \\
\hline LEPIDOPTERA & & 1 & & & \\
\hline NYMPHALIDAE & Dione juno (Cramer 1779) & & 8,9 & 2,4 & 0,4 \\
\hline PIERIDAE & Phoebis s. sennae Linnaeus, 1758 & & 8,9 & 2,1 & 0,5 \\
\hline ARCTIIDAE & Utetheisa ornatrix (Linnaeus, 1758) & & 8,0 & 1,2 & 0,4 \\
\hline \multicolumn{6}{|l|}{ AVES } \\
\hline TROCHILIDAE & & 0,4 & $2,4,5,8,9$ e 13 & & \\
\hline
\end{tabular}

e torna-se maioria ao final do dia. Deste modo, inicialmente as flores podem funcionar como doadoras de pólen e posteriormente como receptoras. Esse mecanismo parece evitar a interferência do pólen disperso pelas anteras sobre a superfície estigmática da mesma flor, no caso de espécies autoincompatíveis como o maracujá-amarelo (Webb \& Lloyd 1986). Os tipos florais totalmente ou parcialmente curvos (denominados TC e PC) são considerados tipos morfológicos receptivos à polinização, já que frutificam quando polinizadas por quaisquer dos três tipos de flores; já as flores do tipo sem curvatura (SC) não formam frutos mesmo quando polinizadas artificialmente apresentando esterilidade feminina e atuando, assim, como flores masculinas (Ruggiero 1973). Os valores de TC, PC e SC encontrados neste estudo foram semelhantes aos encontrados por Ruggiero (1973) e Hoffmann et al. (2000), onde flores com estigmas receptivos totalizaram mais de $90 \%$ das amostragens. Este resultado indica que a proporção de flores sem curvatura não deve ser considerada um fator importante por eventuais porcentagens baixas de polinização natural nas populações estudadas.

A alta concentração de solutos totais encontrados nas flores do maracujá-amarelo pode estar relacionada com as grandes necessidades energéticas das abelhas grandes, seus principais polinizadores (Faegri \& Pijl 1979). Estes foram encontrados durante todo período de produção de néctar.
Maiores freqüências de polinizadores foram observadas até às 14:30 $\mathrm{h}$, quando grande volume de néctar foi produzido.

Os polinizadores mais freqüentes neste estudo foram espécies do gênero Xylocopa, indicadas também em outros trabalhos como os principais polinizadores do maracujáamarelo em diferentes regiões. As abelhas deste gênero habitam diferentes sistemas como florestas, ambientes antrópicos e áreas agrícolas. $X$. frontalis é amplamente distribuída no Brasil, enquanto que $X$. ordinaria está restrita aos domínios da Mata Atlântica envolvendo os estados do RS, SP, RJ, ES e BA (Schlindwein et al. 2003).

A nidificação de $X$. frontalis (Camillo 2003) e de $X$. ordinaria (Bernardino \& Gaglianone 2008) ocorre durante todo o ano, sendo a escolha do substrato relacionada a características favoráveis à nidificação como textura e maciez da madeira e abundância do substrato adequado. Os mourões presentes nas áreas de cultivo podem servir como um importante substrato para a atração de Xylocopa e a sua permanência na área de cultivo ao longo do período de produção do maracujá-amarelo.

O horário de maior atividade de Xylocopa spp. registrado neste estudo foi semelhante ao indicado em outros estudos realizados com espécies deste gênero (Freitas \& Oliveira Filho 2003) embora alguns trabalhos tenham indicado atividade mais tardia, após as 14:00 h (Camillo 1978). 


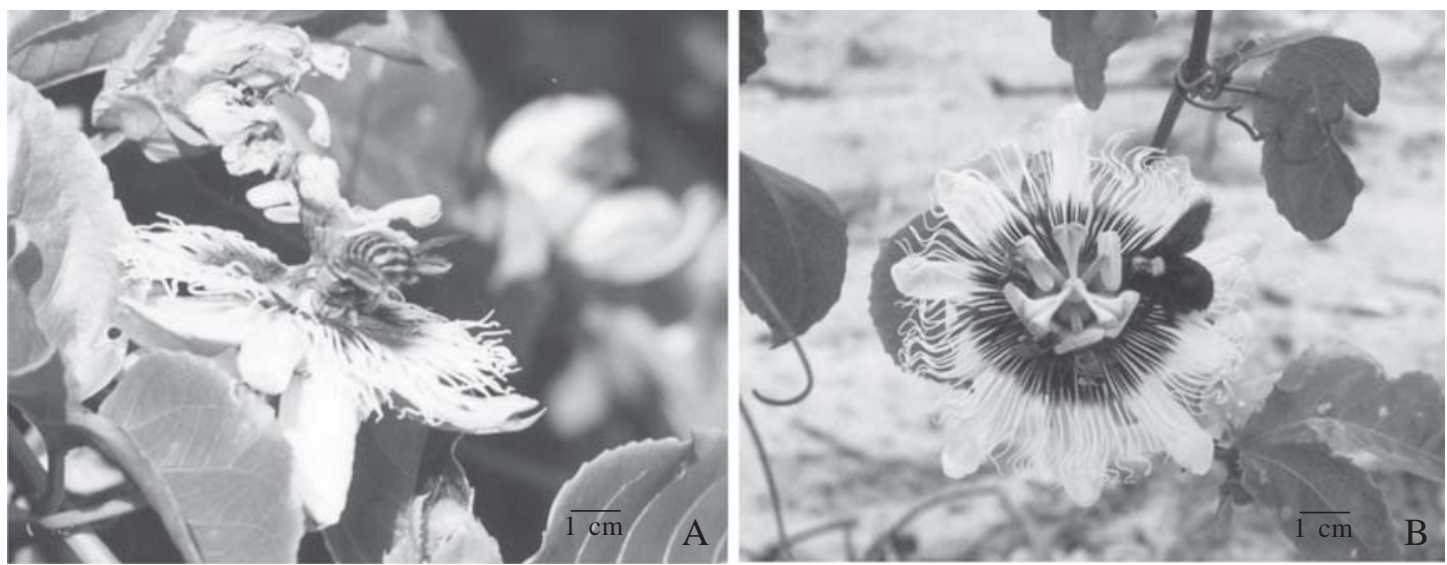

Fig. 7. Visitantes florais de P. edulis f. flavicarpa em áreas de cultivo nos municípios de São Francisco do Itabapoana e Campos dos Goytacazes, RJ. A: Xylocopa frontalis (macho); B: Xylocopa ordinaria e Apis mellifera.

A maior frutificação natural correlacionada ao aumento da freqüência de $X$. frontalis e $X$. ordinaria demonstra o importante papel destas espécies como polinizadores do maracujá-amarelo, devido ao porte corporal e comportamento intra-floral. X. ordinaria apesar de visitar as flores do maracujáamarelo em menor freqüência possui morfologia e comportamento adequados à polinização. Esta espécie mostrou-se muito freqüente em áreas de restinga na região, aumentando possivelmente a sua importância relativa em áreas de cultivo próximas a este ecossistema. Embora estas espécies de Xylocopa não sejam exigentes quanto às fontes de pólen, limitações quanto ao substrato disponível para nidificação podem impor restrições quanto a sua ocorrência e abundância.

A intensa atividade da A. mellifera durante o período de outubro a fevereiro e a baixa atividade nos meses de abril a junho podem estar relacionadas à preferência de forrageio a outras espécies vegetais. A. mellifera possui hábito generalista, forrageamento em grupo e são oportunistas quanto às fontes de recursos; embora a densidade de flores tenha aumentado em abril-junho, a ausência destas abelhas nas flores do maracujá pode ser explicada pela utilização de outras espécies vegetais que florescem intensamente no mesmo período na região, como a aroeira-vermelha (Schinus terebinthifolius Raddi) que são muito atrativas a A. mellifera (Cesário \& Gaglianone 2008).

A. mellifera parece ser prejudicial para as flores do maracujá, devido ao seu comportamento de retirada do pólen das anteras principalmente no início da abertura das flores, embora os resultados não tenham indicado relação significativa entre aumento de atividade desta espécie e diminuição da frutificação. A frequiência destas abelhas durante grande parte da antese foi muito maior do que a observada para os polinizadores, fato esperado devido ao seu comportamento social e recrutamento.

Tabela II. Áreas de cultivo do maracujá-amarelo (Passiflora edulis f. flavicarpa Deg.), distâncias a fragmentos florestais, índices de diversidade de Shannon para cada área e polinizadores encontrados em cada área nos municípios de São Francisco do Itabapoana e Campos dos Goytacazes, RJ. PL: Pontos de localização na figura 1; PFF: Proximidade a fragmento florestal.

\begin{tabular}{|c|c|c|c|c|c|}
\hline Município & PL & PFF & $\mathrm{H}^{\prime}$ & Polinizadores & Paisagem ao redor da área \\
\hline \multirow{6}{*}{$\begin{array}{l}\text { São Francisco do } \\
\text { Itabapoana }\end{array}$} & 2 & $3,6 \mathrm{~km}$ & 0,45 & Xylocopa frontalis & Cana-de-açúcar \\
\hline & & (Mata do Carvão) & & Xylocopa ordinaria & \\
\hline & 4 & $\begin{array}{l}10 \mathrm{~m} \\
\text { (Fragmento florestal) }\end{array}$ & 0,79 & $\begin{array}{l}\text { Xylocopa frontalis } \\
\text { Xylocopa ordinaria } \\
\text { Epicharis flava } \\
\text { Centris flavifrons } \\
\text { Centris longimana }\end{array}$ & $\begin{array}{l}\text { Fragmento florestal, } \\
\text { cana-de-açúcar e mandioca }\end{array}$ \\
\hline & 5 & $\begin{array}{l}\text { 1,4 km } \\
\text { (Mata do Carvão) }\end{array}$ & 0,79 & $\begin{array}{l}\text { Xylocopa frontalis } \\
\text { Xylocopa ordinaria } \\
\text { Eulaema nigrita }\end{array}$ & cana-de-açúcar e mandioca \\
\hline & 8 & $\begin{array}{l}1 \mathrm{~km} \\
\text { (Mata do Funil) }\end{array}$ & 0,65 & $\begin{array}{l}\text { Xylocopa frontalis } \\
\text { Xylocopa ordinaria }\end{array}$ & cana-de-açúcar e abacaxi \\
\hline & 9 & $\begin{array}{l}600 \mathrm{~m} \\
\text { (Mata do Funil) }\end{array}$ & 0,59 & $\begin{array}{l}\text { Xylocopa frontalis } \\
\text { Xylocopa ordinaria } \\
\text { Centris flavifrons }\end{array}$ & cana-de-açúcar e abacaxi \\
\hline $\begin{array}{l}\text { Campos dos } \\
\text { Goytacazes }\end{array}$ & 13 & $\begin{array}{l}3,2 \mathrm{~km} \\
\text { (Mata do Bom Jesus) }\end{array}$ & 0,65 & $\begin{array}{l}\text { Xylocopa frontalis } \\
\text { Xylocopa ordinaria } \\
\text { Eulaema cingulata }\end{array}$ & cana-de-açúcar, mandioca e pasto \\
\hline
\end{tabular}


Além de Xylocopa, foram evidenciadas outras espécies de grande porte, de Euglossina e Centridini, como potenciais polinizadores, fato relatado por outros autores para diferentes regiões do Brasil (Camillo 1978; Hoffmann et al. 2000).

Maior diversidade de polinizadores foi observada em duas áreas mais próximas de fragmentos florestais em São Francisco do Itabapoana nas áreas 4 (a $10 \mathrm{~m}$ ) e 5 (a 1,4 km). Entretanto, as correlações negativas entre diversidade/riqueza e distância não foram significativas, resultado provavelmente obtido pelo baixo número de áreas amostradas. Porém, foi observada a ausência de alguns grupos, como abelhas Centridini, nas áreas de cultivo mais distantes dos fragmentos florestais. Embora de ampla ocorrência, estas espécies necessitam de recursos florais específicos como óleos (no caso de Centridini), além de substratos específicos para nidificação como termiteiros (Centris longimana), ou tipos específicos de solo (Centris flavifrons, Epicharis nigrita e E. flava) (Camargo et al. 1975; Coville et al. 1983; Gaglianone 2005). No caso de Xylocopa spp., estas exigências podem ser menores já que utilizam muitas fontes de pólen e os substratos de nidificação podem ser encontrados na área de cultivo, mesmo na madeira das espaldeiras que sustentam a plantação de maracujá-amarelo. Entretanto, a proximidade aos fragmentos florestais pode favorecer a manutenção de grandes populações destas abelhas, através da oferta de recursos diversificados ao longo do ano, como observado por Menezes \& Gaglianone (com. pes.), inclusive em períodos de ausência de florescimento do maracujá-amarelo na região.

Agradecimentos: A fonte financiadora do projeto: PROBIOPolinizadores/MMA (Convênio 0115-00/04), ao Laboratório de Ciências Ambientais (UENF) pelo apoio logístico e confecção do mapa (setor de geoprocessamento), FAPERJ pela bolsa de mestrado, Elisabeth Vidal Fernandes pela ajuda no campo, aos agricultores pela permissão para o trabalho nas suas propriedades, ao Programa de Pós-Graduação em Ecologia e Recursos Naturais (UENF).

\section{REFERÊNCIAS}

Bernardino, A. S. \& M. C. Gaglianone. 2008. Nest distribution and nesting habits of Xylocopa ordinaria Smith (Hymenoptera, Apidae) in a restinga area in the northern Rio de Janeiro State, Brazil. Revista Brasileira de Entomologia 52: 434-440.

Camargo, J. M. F.; R. Zucchi \& S. F. Sakagami. 1975. Observations on the bionomics of Epicharis (Epicharana) rustica flava (Oliver) including notes on its parasite Rhathymus sp. (Hymenoptera, Apoidea: Anthophoridae). Studia Entomologica 18: 313-340.

Camillo, E. 1978. Estudos sobre o incremento da população de polinizadores de maracujá (Hymenoptera, Anthophoridae). Ciência e Cultura 30: 594

Camillo, E. 2003. Polinização do maracujá. Ribeirão Preto, Holos Editora, $44 \mathrm{p}$.

Cesário, L. F. \& M. C. Gaglianone. 2008. Biologia floral e fenologia reprodutiva de Schinus terebinthifolius Raddi (Anacardiaceae) em Restinga do Norte Fluminense. Acta Botanica Brasilica 22: 828833.

Chacoff, N. P. \& M. A. Aizen. 2006. Edge effects on flower-visiting insects in grapefruit plantations bordering premontane subtropical

Recebido em 18/09/2008; aceito em 23/04/2009 forest. Journal of Applied Ecology 43: 18-27.

Corbet, S. A. \& P. G. Willmer. 1980. Pollination of the yellow passion fruit: Nectar, pollen and carpenter bees. Journal of Agricultural Science 95: 655-666.

Coville, R. E.; G. W. Frankie \& S. B. Vinson. 1983. Nets of Centris segregata (Hymenoptera: Anthophoridae) with a review of the nesting habitats of the genus. Journal of the Kansas Entomological Society 56: 109-122.

Cresswell, J. E. \& J. L. Osborne. 2004. The effect of patch size and separation on bumblebee foraging in oilseed rape: implications for gene flow. Journal of Applied Ecology 41: 539-546.

Debinsky, D. M. \& R. D. Holt. 2000. A survey and overview of habitat fragmentation experiments. Conservation Biology 14: 342-355.

Faegri, K. \& L. V. D. Pij1. 1979. The Principles of Pollination Ecology. Third Revised Edition. Oxford. Pergamon Press, 244 p.

Ferreira, V. R.; P. M. Souza; N. J. Ponciano \& A. J. C. Carvalho. 2003. A fruticultura como alternativa para a produção familiar no âmbito do Pronaf nos municípios de Campos dos Goytacazes e São Francisco do Itabapoana, RJ. Revista Brasileira Fruticultura 25: 436439.

Freitas, B. M. \& J. H. Oliveira Filho. 2003. Ninhos racionais para mamangava (Xylocopa frontalis) na polinização do maracujáamarelo (Passiflora edulis) Ciência Rural 33: 1135-1139.

Gaglianone, M. C. 2005. Nesting biology, seasonality and flower hosts of Epicharis nigrita, with a comparative analysis for the genus. Studies on Neotropical Fauna and Environment 40: 191200.

Hoffmann, M.; T. N. S. Pereira; M. B. Mercadante \& A. R. Gomes. 2000. Polinização de Passiflora edulis f. flavicarpa (Passiflorales, Passifloraceae), por abelhas (Hymenoptera, Anthophoridae) em Campos dos Goytacazes, Rio de Janeiro. Iheringia 89: 149-152.

Kevan, P. G. 1999. Pollinators as bioindicators of the state of the environment: species, activity and diversity. Agriculture, Ecosystems and Environment 74: 373-393.

Klein, A. M.; I. Steffan-Dewenter \& T. Tscharntke. 2003. Pollination of Coffea canephora in relation to local and regional agroforestry management. Journal of Applied Ecology 40: 837-845.

Magurran, A. E. 1988. Ecological Diversity and Its Measurement. Princeton, Princeton University Press, 179 p.

Rizzini, C. T. 1979. Tratado de Fitogeografia do Brasil. V.2. Aspectos ecológicos. São Paulo. Hucitec/ Edusp, 327 p.

Roubik, D. W. 1995. Pollination of cultivated plants in the tropics. FAO Agricultural Services Bulletin, V. 118. Rome, Food and Agriculture Organization of the United Nations, $198 \mathrm{p}$.

Ruggiero, C. 1973. Estudo sobre floração e polinização do maracujá-amarelo (Passiflora edulis f. flavicarpa Deg.). Tese de doutorado, Jaboticabal, FCAV, 92 p.

Schlindwein, C.; B. Schlumpberger; D. Wittmann \& J. S. Moure. 2003. O gênero Xylocopa Latreille no Rio Grande do Sul, Brasil (Hymenoptera, Anthophoridae) Revista Brasileira de Entomologia 47: 107-118.

Silva, G. C. \& M. T. Nascimento. 2001. Fitossociologia de um remanescente de mata sobre tabuleiro no Norte do Estado do Rio de Janeiro (Mata do Carvão). Revista Brasileira de Botânica 24: $51-62$.

Sousa, P. J. S. 1994. Polinização em maracujazeiro, p. 65-70. In: São José, A. R. (ed.). Maracujá, produção e mercado. Vitória da Conquista, DFZ/UESB, 255 p.

Teixeira, C. G. 1994. Multiplicação, p. 125. In: ITAL. Maracujá: cultura, matéria prima, processamento e aspectos econômicos. Campinas, Instituto de Tecnologia de Alimentos, $42 \mathrm{p}$.

Vallini, P. C.; A. L. Sanchez \& C. F. R. Ruggiero. 1976. Studies on the flowering period of yellow passion fruit (Pasiflora edulis $\mathrm{f}$. flavicarpa Deg.) in the region of Jaboticabal, São Paulo. Acta Horticulturae. 57: 233-236.

Webb, C. J. \& D. G. Lloyd. 1986. The avoidance of interference between the presentation of pollen and stigmas in angiosperms II. Herkogamy. New Zeland Journal of Botany 24: 163-178.

Zar, J. H. 1999. Biostatistical Analysis. $4^{\circ}$ Ed. New Jersey, Prentice Hall, $663 \mathrm{p}$ 